\title{
Strength and permeation properties of slag blended fly ash based geopolymer concrete
}

\author{
Partha Sarathi Deb", a , Pradip Nath ${ }^{1, b}$ and Prabir Kumar Sarker ${ }^{1, c}$ \\ ${ }^{1}$ Department of Civil Engineering, Curtin University, Kent Steet, Bentley 6102, Perth, Australia. \\ apartha.deb@postgrad.curtin.edu.au, b pradip.nath@postgrad.curtin.edu.au, \\ cp.sarker@.curtin.edu.au
}

Keywords: Ambient curing, fly ash, geopolymer, slag, sorptivity, permeation.

\begin{abstract}
Geopolymer is a binder that can act as an alternative of Portland cement. Geopolymers use by-product substances such as fly ash, and can help reduce carbon di oxide emission of concrete production. This paper presents the results of a study on the fly ash based geopolymer concrete suitable for curing at ambient temperature. To activate the Silicon and Aluminium content in fly ash, a combination of sodium hydroxide and sodium silicate solutions was used. The setting and hardening of geopolymer concrete were obtained by blending blast furnace slag with fly ash instead of using heat curing. Ground granulated blast furnace slag was used at the rate of $10 \%$ or $20 \%$ of the total binder. The tests conducted include compressive strength, tensile strength, flexure strength, sorptivity and volume of permeable voids (VPV) test. The geopolymer concrete compressive strength at 28 days varied from 27 to $47 \mathrm{MPa}$. Results indicated that the water absorption decreased with an increase of the slag content in the mixtures and eventual increase in strength of the geopolymer concrete. The results show that blending of slag with fly ash in geopolymer concrete improved strength and permeation properties when cured in ambient temperature.
\end{abstract}

\section{Introduction}

Geopolymer concrete can play a vital role in the context of sustainability and environmental issues. Approximately $5 \%$ of global $\mathrm{CO}_{2}$ emissions originate from the manufacturing of cement. Use of geopolymer as a binder can reduce the greenhouse gas emission of concrete. Geopolymer concrete can be produced using the current concrete technology without any significant changes. However, some alkaline liquids are required in order to activate the fly ash to obtain the geopolymeric binder. The most common alkaline activator used in geopolymerisation is a combination of sodium hydroxide $(\mathrm{NaOH})$ and sodium silicate.

The compressive strength of geopolymer concrete usually increases with the increase of concentration of $\mathrm{NaOH}$ solution, ratio of sodium silicate to sodium hydroxide, mixing time, curing temperature and curing time [1]. The values of density, modulus of elasticity, stress strain relationship and poison's ratio for geopolymer concrete were found to be similar to those of OPC concrete.

Most of the previous studies were conducted on heat-cured geopolymer concrete that is considered to be ideal for precast concrete members. Fly ash based geopolymer cured in ambient temperature showed lower strength gain at early ages as compared to heat-cured specimens [2]. Slow setting and strength gain are the main drawbacks of fly ash based geopolymer concrete when cured at ambient temperature. Hence this study attempted to produce geopolymer concrete suitable for ambient curing condition. Ground granulated blast furnace slag was mixed with low calcium fly ash instead of elevated heat to accelerate the curing of geopolymer concrete. Mechanical properties such as compressive, tensile and flexure strengths, and permeation properties such as sorptivity and volume of permeable voids of geopolymer concrete were studied. 


\section{Experimental Work}

Materials: Low calcium Class F (ASTM C 618) fly ash was used for making geopolymer concrete. GGBFS was added to fly ash to study its effect on the strength and permeation properties of concrete. The chemical compositions of the fly ash and slag are given in Table 1. The alkaline liquid used for geopolymerisation was a combination of sodium hydroxide $(\mathrm{NaOH})$ and sodium silicate. The sodium hydroxide solution of $14 \mathrm{M}$ concentration was prepared by dissolving the flakes of $\mathrm{NaOH}$ in water. Sodium silicate solution obtained from a local supplier was used. The mass chemical composition of the sodium silicate solution was $11.5 \% \mathrm{Na}_{2} \mathrm{O}, 30.0 \% \mathrm{SiO}_{2}$ and $58.5 \%$ water. Fine aggregate was river sand with fineness modulus of 1.97. Coarse aggregates were crushed granite with nominal maximum size of 7, 10 and $20 \mathrm{~mm}$ that met the Australian Standard specifications [3]. The fineness modulus of the combined aggregates was 6.12. Normal tap water and a naphthalene sulphonate polymer-based superplasticiser were used.

Table 1: Chemical composition of fly ash \& GGBFS

\begin{tabular}{|l|l|l|l|l|l|l|l|l|l|l|l|}
\hline Sample & $\mathrm{SiO}_{2}$ & $\mathrm{Al}_{2} \mathrm{O}_{3}$ & $\mathrm{Fe}_{2} \mathrm{O}_{3}$ & $\mathrm{CaO}$ & $\mathrm{MgO}$ & $\mathrm{Na}_{2} \mathrm{O}$ & $\mathrm{K}_{2} \mathrm{O}$ & $\mathrm{SO}_{3}$ & $\mathrm{P}_{2} \mathrm{O}_{5}$ & $\mathrm{TiO}_{2}$ & $\mathrm{LOI}^{\mathrm{a}}$ \\
\hline Fly ash [\%] & 50.00 & 28.25 & 13.5 & 1.79 & 0.89 & 0.32 & 0.46 & 0.38 & 0.98 & 1.54 & 0.64 \\
\hline GGBFS [\%] & 32.46 & 14.3 & 0.61 & 43.1 & 3.94 & 0.24 & 0.33 & 4.58 & 0.02 & 0.55 & 0.09 \\
\hline
\end{tabular}

${ }^{\mathrm{a}}$ Loss of ignition

Table 2: Details of geopolymer concrete mix proportions $\left(\mathrm{kg} / \mathrm{m}^{3}\right)$

\begin{tabular}{|c|c|c|c|c|c|c|c|c|c|c|c|c|c|c|}
\hline \multicolumn{2}{|c|}{ Mixture } & \multicolumn{8}{|c|}{ Ingredients } & \multicolumn{3}{|c|}{ Molar ratio } & \multirow[b]{2}{*}{$\mathrm{w} / \mathrm{s}^{\mathrm{e}}$} & \multirow{2}{*}{$\begin{array}{c}\text { Slum } \\
\mathrm{p} \\
(\mathrm{mm})\end{array}$} \\
\hline ID & Label & $\mathrm{CA}^{\mathrm{a}}$ & Sand & $\begin{array}{l}\text { Fly } \\
\text { ash }\end{array}$ & Slag & $\mathrm{SS}^{\mathrm{b}}$ & $\mathrm{SH}^{\mathrm{c}}$ & water & $\mathrm{SP}^{\mathrm{d}}$ & $\begin{array}{l}\mathrm{Na}_{2} \mathrm{O} / \\
\mathrm{SiO}_{2} \\
\end{array}$ & $\begin{array}{l}\mathrm{H}_{2} \mathrm{O} / \\
\mathrm{Na}_{2} \mathrm{O} \\
\end{array}$ & $\mathrm{Si} / \mathrm{Al}$ & & \\
\hline GPC1 & 40 & 1209 & 651 & 360 & 40 & 14.3 & 45.7 & 0 & 0 & 0.122 & 11.78 & 1.795 & 0.202 & 230 \\
\hline GPC2 & A40 S20 & 1209 & 651 & 320 & 80 & 114.3 & 45.7 & 0 & 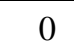 & 0.126 & 11.79 & 1.835 & 0.202 & 220 \\
\hline GPC3 & A35 S10 & 1217 & 655 & 360 & 4 & 10 & 40 & 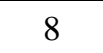 & 0 & 0.11 & 12.79 & 1.76 & 0.197 & 210 \\
\hline GPC4 & A 35 S20 & 1217 & 655 & 320 & 80 & 100 & 40 & 8 & 6 & 0.113 & 12.81 & 1.8 & 0.197 & 200 \\
\hline
\end{tabular}

${ }^{\mathrm{a}}$ Coarse aggregate; ${ }^{\mathrm{b}}$ Sodium silicate solution; ${ }^{\mathrm{c}}$ Sodium hydroxide solution; ${ }^{\mathrm{d}}$ Superplasticiser; ${ }^{\mathrm{e}} \mathrm{W}$ ater to solid ratio

Manufacture of geopolymer concrete: The mixture proportions of geopolymer concrete mixtures are given in Table 2. Mixture GPC1, GPC2, GPC3 and GPC4 were designed with a constant sodium silicate to sodium hydroxide ratio of 2.5 and with $10 \%$ or $20 \%$ slag in the fly ash-slag blend. The alkaline activator was either $35 \%$ or $40 \%$ of the binder. The geopolymer mixtures were designated with their variable constituents in the mixture. For example, A35 S20 represents a geopolymer concrete mixture having alkaline activator solution (A) as $35 \%$ of total binder and slag (S) as $20 \%$ of fly ash-slag blend.

The alkaline activator solutions were mixed together prior to adding to the dry materials. The fly ash and the aggregates were first mixed together in the pan mixer. This was followed by the addition of the activator solutions to the dry materials and the mixing continued for further about 3-5 minutes to produce fresh concrete. Geopolymer mixture with 35\% alkaline activator was relatively sticky in nature. To improve the workability of the mixtures super plasticizer and extra water were added. The workability of the fresh concrete mixtures was determined by slump test [4]. The specimens were cast for compressive strength [5], splitting tensile strength [6], flexure strength [7], volume of permeable void (VPV) [8] and sorptivity tests [9]. All the specimens were cured at 17-22 ${ }^{\circ} \mathrm{C}$ and $70 \pm 10 \%$ relative humidity. Three specimens were produced for each test and the results were reported as the average of three specimens. 


\section{Results and Discussion}

Workability of fresh concrete: Slump test was conducted immediately after mixing of each geopolymer concrete. Generally geopolymer concrete mixtures showed sticky and viscous behaviour in fresh state. Slump value increased with the increase of the activator liquid content in the mix. Slump was also influenced by the slag content in the mixture and decreased with the increase of slag content. Hence extra water and superplasticiser were added to improve workability of the mixtures having 35\% alkaline liquid. Geopolymer concrete GPC4 with 20\% slag and SS/SH ratio of 2.5 exhibited low slump value than the other mixtures (Table 2).

Compressive strength: Compressive strength test was done at 7, 28, 56 and 90 days. Strength at 28 days varied in the range of 27-47 MPa. Compressive strength of GPC1 with $40 \%$ alkaline activator varied with the variation of slag content in the mixture. As shown in Figure 1, the compressive strength of geopolymer concrete mixture increased from the early age of 7 days and continued to gain strength up to 90 days. At 28 days, Mixture GPC2 having 20\% slag achieved $15 \%$ higher strength as compared to strength of GPC1 (10\% slag). Strength of geopolymer mixtures GPC3 and GPC4 with $35 \%$ alkaline activator reflected the same strength increment like GPC1 and GPC2 due to different percentage of slag replacement.

Table 3 Compressive strength $\left(f_{c}^{\prime}\right)$

\begin{tabular}{|c|c|c|c|c|}
\hline \multirow{2}{*}{ Mix no } & \multicolumn{4}{|c|}{ Compressive strength $f^{\prime}{ }_{c}[\mathrm{MPa}]$} \\
\cline { 2 - 5 } & 7 day & 28 day & 56 day & 90 day \\
\hline GPC1 & 26.9 & 40.4 & 44.7 & 47.2 \\
\hline GPC2 & 31.3 & 46.6 & 50.3 & 54.3 \\
\hline GPC3 & 14.5 & 27.0 & 34.9 & 37.7 \\
\hline GPC4 & 22.1 & 34.7 & 39.6 & 42.7 \\
\hline
\end{tabular}

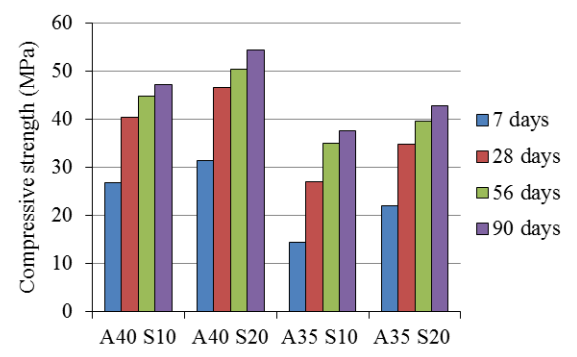

Figure 1: Development of Compressive strength of the geopolymer concretes.

The Compressive strength of geopolymer concrete is significantly influenced by the amount of alkaline activator in the mixture. Decreasing the activator content from $40 \%$ to $35 \%$ of the binder without adding any extra water generally increases strength of geopolymer concrete [10]. Comparing the results of GPC2 and GPC4, it can be seen that GPC4 with reduced alkaline activator resulted in less compressive strength than the GPC2. The reduction of compressive strength of GPC4 is due to the increase of water to $\mathrm{Na}_{2} \mathrm{O}$ ratio. The additional water also decreased $\mathrm{NaOH}$ concentration in the mixture. From Table 2 it can be noted that adding extra water of $8 \mathrm{~kg} / \mathrm{m}^{3}$ in GPC 4 increased the water to $\mathrm{Na}_{2} \mathrm{O}$ ratio as compared to GPC2. Hence presence of free water affected the strength by reducing $\mathrm{NaOH}$ concentration which caused reduced reactivity for geopolymerisation.

Splitting Tensile strength: The splitting tensile strengths of the geopolymer concrete are given in Table 4. The tensile strength results followed similar trend of compressive strength of the geopolymer concrete and increased with increase of age. Moreover, it can be observed from Table 4 that the experimentally determined values of splitting tensile strength are above the tensile strength $\left(f_{c t}^{\prime}\right)$ values calculated by using Eq. 1 as per AS 3600 [11].

$$
f^{\prime}{ }_{c t}=0.4 \times\left(f^{\prime}{ }^{\prime}\right)^{0.5}
$$


It can be seen from Figure 2 that the use of slag as partial replacement of fly ash improved the splitting tensile strength of geopolymer concrete. The rate of strength development was slightly higher for GPC2 than GPC1 which continued up to 90 days of age. Geopolymer concrete mixtures GPC3 and GPC4 also showed strength improvement as the slag content increased from $10 \%$ to $20 \%$. Again, the trend of the variation of splitting tensile strength was similar to that of compressive strength.

Table 4 Tensile strength results

\begin{tabular}{|c|c|c|c|c|}
\hline \multirow{2}{*}{ Mix no } & \multicolumn{4}{|c|}{ Indirect Tensile Strength [MPa] } \\
\cline { 2 - 5 } & 7 day & 28 day & 90 day & Theoretical value at 28 day \\
\hline GPC1 & 2.36 & 3.09 & 3.43 & 2.54 \\
\hline GPC2 & 2.48 & 3.25 & 3.50 & 2.73 \\
\hline GPC3 & 1.43 & 2.16 & 2.61 & 2.07 \\
\hline GPC4 & 1.43 & 3.02 & 3.28 & 2.35 \\
\hline
\end{tabular}

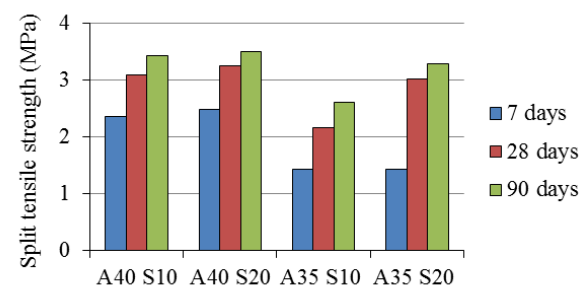

Figure 2: Development of tensile strength of different geopolymer concretes mixtures.

Flexural strength: The average flexural strength values of the geopolymer concrete mixtures for 7 , 28 and 90 days of age are given in Table 5. It can be observed that the addition of GGBFS in different amounts increased the flexural strength of geopolymer concretes. The effect of inclusion of GGBFS on the flexural strength followed the same general trend as the compressive strengths of geopolymer mixtures. Mixes designed with 35\% alkaline activator and extra water (GPC3 and GPC4) achieved slightly less flexural strength than those having 40\% alkaline activator (GPC1 and GPC2 respectively), however the reduction was less significant than the reduction in compressive strength of the mixtures.

Table 5: Flexural strength results

\begin{tabular}{|c|c|c|c|c|}
\hline \multirow{2}{*}{ Mix no } & \multicolumn{4}{|c|}{ Flexural Strength [MPa] } \\
\cline { 2 - 5 } & 7 day & 28 day & 90 day & Theoretical value at 28 day \\
\hline GPC1 & 3.20 & 4.68 & 4.94 & 1.29 \\
\hline GPC2 & 3.60 & 4.92 & 5.27 & 1.33 \\
\hline GPC3 & 3.18 & 3.85 & 4.66 & 1.17 \\
\hline GPC4 & 3.04 & 4.22 & 4.90 & 1.23 \\
\hline
\end{tabular}

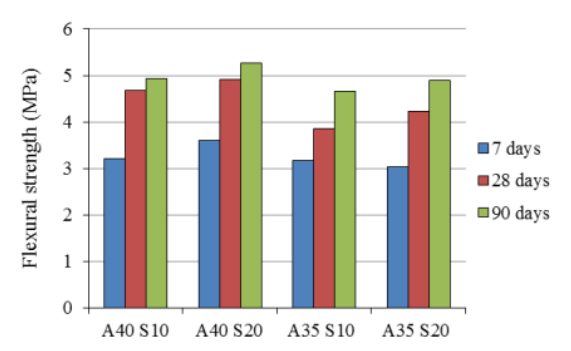

Figure 3: Development of flexural strength of different geopolymer concretes mixtures 
The 28-day flexural strength values obtained from the test were compared with the theoretical values calculated by the equation (Eq. 2) which is principally provided for OPC concrete [11]. The values are given in table 4 . All mixtures showed much higher strength in test than that predicted by the equation.

$$
f_{c f}^{\prime}=0.60 \times\left(f^{\prime}{ }^{\prime}\right)^{0.5}
$$

Volume of Permeable Voids (VPV): The VPV tests of the geopolymer concrete specimens were conducted at 28 days of age and are plotted in Figure 4. It can be observed from Figure 4 that the VPV of geopolymer concretes varied with the compressive strength of geopolymer mixtures. The mixture GPC2 with $20 \%$ slag showed smaller VPV value than mixture GPC1 with $10 \%$ slag.

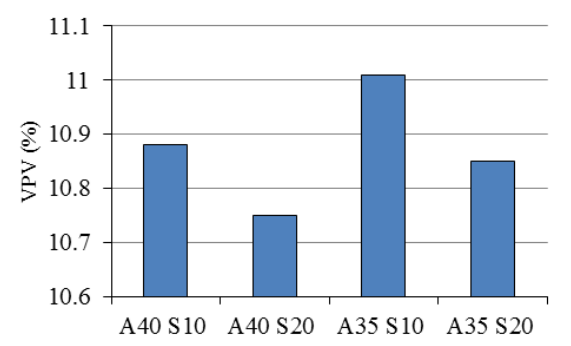

Figure 4: VPV of ambient-cured geopolymer concrete at 28-days

It can be noted from Figure 4 that, extra water in GPC3 and GPC4 influenced the pore formation in the geopolymer concrete which ultimately increased the volume of permeable voids as compared to mixtures having no added water. However, the values of VPV except GPC3 were less than 11\% which were classified as "excellent" concretes according to VicRoads classification for concrete durability based on the VPV of vibrated cylinders [12]. Mixture GPC3 was just at the margin of 11$13 \%$ which were classified as "good" concrete [12].

Sorptivity: Sorptivity tests were done at the age of 28 days. Figure 5 shows the comparison of sorptivity of different geopolymer concrete mixtures with different alkaline activator and slag content. Comparing the results of geopolymer concrete mixtures GPC1, GPC2, GPC3 and GPC4, it can be seen that sorptivity values decreased with the increase of compressive strength of geopolymer mixtures. Resistance to permeation increased with the increase of slag content in the mixture. However mixtures having 35\% solution with extra water showed higher sorptivity as compared to those having $40 \%$ solution with no extra water. The sorptivity values can be improved by a decrease in the water content and an increase in binder content [13].

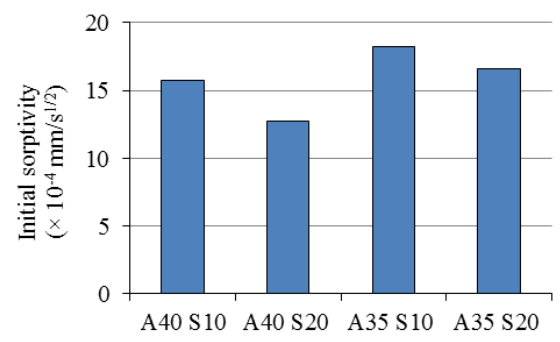

Figure 5: Sorptivity of ambient-cured geopolymer concrete at 28-days

Papworth and grace (1985) [14] recommended the typical values of sorptivity for various performances of concrete. This recommendations are used in this study to rate the quality of the concretes. The geopolymer concrete mixtures can be classified as "very good", as the co-efficient of sorptivity values are less than $129.1 \times 10^{-4} \mathrm{~mm} / \mathrm{sec}^{1 / 2}[14]$. 


\section{Conclusion}

Four geopolymer concrete mixtures were designed with fly ash and slag blend as the binder source material. Compressive strength, tensile strength, flexure strength, sorptivity and VPV of ambient-cured geopolymer concrete were compared with the variation of slag content and alkaline activator content for a constant ratio of sodium hydroxide to sodium silicate solutions. The results are summarised below:

1) Compressive strength of geopolymer concrete increased with the increase of slag content. The addition of extra water and naphthalene based superplasticiser improves the workability of the fresh geopolymer concrete; however, addition of extra water with reduced alkaline solution decreased the compressive strength of geopolymer concrete.

2) The incorporation of slag in the fly ash based geopolymer concrete increased flexural and tensile strengths. The test results are higher than the values calculated by the equations given in AS 3600.

3) The 28-day permeation properties such as the sorptivity and VPV values decreased with the increase of slag content. Both sorptivity and VPV values decreased with the increase of compressive strength.

\section{Acknowledgement}

The authors wish to gratefully acknowledge the support provided by Coogee Chemicals, Western Australia.

\section{Reference:}

[1] Hardjito, D: Studies on fly ash-based geopolymer concrete. $\mathrm{PhD}$ thesis, Curtin University of technology, (2005).

[2] Vijai, K., Kumuthal, R. and Vishnuram, B. G: Effect of types of curing on strength of geopolymer concrete. International Journal of the Physical Sciences, Vol. 5(9), pp. 1419-1423, (2010).

[3] AS 2758.1: Aggregates and rock for engineering purposes - Concrete aggregates. Standard Australia, (1998)

[4] ASTM C 143/C143M: Standard Test Method for Slump of Hydraulic-Cement Concrete. ASTM International. (2010)

[5] AS 1012.9: Methods of testing concrete - Determination of the compressive strength of concrete specimens. Standard Australia, (1999)

[6] AS 1012.10 : Methods of testing concrete - Determination of indirect tensile strength of concrete cylinders. Standard Australia, (2000)

[7] AS 1012.11: Methods of testing concrete - Determination of the modulus of rupture. Standard Australia, (2000)

[8]AS 1012.21: Methods of testing concrete - Determination of water absorption and apparent volume of permeable voids in hardened concrete (1999)

[9] AS 1012.21: Methods of testing concrete - Determination of water absorption and apparent volume of permeable voids in hardened concrete. Standard Australia, (1999)

[10] Nath. P and Sarker.P. Geopolymer Concrete for ambient Curing Condition. Proceeding of Australasian Structural Engineering (ASEC 2012), July 11-13, 2012, Perth, Australia.

[11] AS 3600: Concrete structures. Standard Australia, (2009)

[12] Concrete institute of Australia: Performance criteria for concrete in Marine Environments. Sydney, Concrete institute of Australia (2001)

[13] Olivia, M \& Nikraz, H.R: Corrosion performance of the embedded steel in fly ash geopolymer concrete by impressed voltage method. In Incorporating Sustainable Practice in Mechanics of Structures and Materials - Fragomeni, Venkatesan, Lam \& Setunge (eds). Taylor \& Francis group, London. (2011) 
[14] Papworth, F, \& Grace, W. Designing for concrete durability in Marine Environments. Concrete 85 Conference, Brisbane, (1985)

[15] Rangan, B. V. and Wallah, S. E: Low-Calcium fly ash-based Geopolymer Concrete: Long-Term properties. Research Report GC 2, Curtin University of Technology. (2006) 